$3 \quad$ Morphology of the canine omentum part 1: Arterial landmarks

\title{
that define the omentum
}

5

M. Doom ${ }^{1}$, H. de Rooster ${ }^{2}$, T. van Bergen ${ }^{3}$ Ingrid Gielen $^{4}$, Kaatje Kromhout ${ }^{4}$, P. Simoens $^{1}$ and P. Cornillie ${ }^{1}$

\footnotetext{
${ }^{1}$ Department of Morphology, Faculty of Veterinary Medicine, Ghent University, Ghent, Belgium
}

${ }^{2}$ Department of Medicine and Clinical Biology of Small Animals, Faculty of Veterinary Medicine, Ghent University, Ghent, Belgium

${ }^{3}$ Department of Surgery and Anaesthesiology, Faculty of Veterinary Medicine, Ghent University, Ghent, Belgium

${ }^{4}$ Department of Veterinary Medical Imaging and Small animal orthopaedics, Faculty of Veterinary Medicine, Ghent University, Belgium

Corresponding author:

Marjan Doom, DVM

Marjan.Doom@UGent.be

Salisburylaan 133, B-9820 Merelbeke, Belgium

Tel : 0032(0)9/264.77.14

Fax : 0032(0)9/264.77.90

\section{Figures}

1 Video 


\section{$\underline{\text { Summary }}$}

Although the omentum remains an enigmatic organ, research during the last decades has revealed its fascinating functions including fat storage, fluid drainage, immune activity, angiogenesis and adhesion. While clinicians both in human and veterinary medicine are continuously exploring new potential omental applications, detailed anatomical data on the canine omentum are currently lacking and information is often retrieved from human medicine. In the present study, the topographic anatomy of the canine greater and lesser omentum is explored in depth. Current nomenclature is challenged and a more detailed terminology is proposed. Consistent arteries that are contained within folds of the superficial omental wall are documented, described and named, as they can provide the anatomical landmarks that are necessary for unambiguous scientific communication on the canine omentum. In an included dissection video, the conclusions and in situ findings described in the present study are demonstrated.

Key words: Anatomy - Arteries - Canine - Omentum

\section{$\underline{\text { Introduction }}$}

The greater and lesser omentum (Omentum majus and Omentum minus) are peritoneal sheets that originate from the embryonic dorsal and ventral mesogastrium, respectively (Evans, 1993; McGready et al., 2006; Barone, 2009). During fetal development, the mesogastria lose their initial role of anchoring the stomach to the dorsal and ventral body walls. They are charged with blood vessels and lymphatics that run in fatty streaks. As the greater curvature of the developing stomach topples to its final position, the dorsal mesogastrium elongates and is drawn to the left. Its double layer of mesothelium reflects, lining a cavity that will become the omental bursa (Bursa omentalis). From this stage of development onwards, the dorsal 
mesogastrium consists of a superficial and a deep wall (Noden and De Lahunta, 1985; McGready, 2006).

In dogs, the greater omentum is remarkably large and extends as a double-folded structure from the stomach to the urinary bladder, covering the intestinal coils ventrally and bilaterally. The greater omentum is classically subdivided into a bursal, a splenic and a veil portion (Zietzschmann, 1939; Evans, 1993; Budras, 2002; Barone, 2009). The bursal and splenic portions are composed of two walls, viz. a superficial wall (Paries superficialis) and a deep wall (Paries profundus) (Budras, 2002). In the veil portion, however, both walls fuse during embryonic development (Zietzschmann, 1939). The lesser omentum is small and relatively simple. It spans the area lined by the liver, the lesser curvature of the stomach and the cranial part of the duodenum (Barone, 2009). Based on the site of attachment, it is subdivided into the hepatogastric ligament (Ligamentum hepatogastricum) and the hepatoduodenal ligament (Ligamentum hepatoduodenale), the latter of which contains the portal vein, the hepatic artery and the common bile duct (Evans, 1993; Barone, 2009).

After Otto Zietzschmann meticulously described the topographical anatomy of the canine omentum in 1939, some nomenclature introduced in this pioneer study is no longer commonly applied, and little additional research has been performed on the gross anatomy of the omentum of the dog. However, there is a need for more detailed anatomical data since surgical applications of the omentum are continuously being developed not only in human medicine (Liebermann-Meffert, 2000) but also in small animal veterinary medicine (Valat and Moisonnier, 2004). The anatomy and physiology of the omentum turn the organ into a very beneficial tool for a variety of intra- and extra-abdominal surgical procedures (Fix and Vasconez, 1989; Ross and Pardo, 1993; Hultman et al., 2002; Ito et al., 2010). Due to its large surface area, pliability, malleable volume, generous pedicle length and extremely rich blood supply, the omentum is particularly fit to treat infected, irradiated and ischemic wounds such 
as radiation injuries of the chest wall in humans (Fix and Vasconez, 1989; Hultman et al., 2002) or chronic axillary wounds in cats (Gray, 2005). In dogs, the omentum is also used as a physiological drain in the surgical management of prostatic abscesses and cysts (White and Williams, 1995). Moreover, the omentum is a reservoir of peritoneal immune cells and a source of angiogenic and neurotrophic factors (De la Torre and Goldsmith, 1988; Zhang et al., 1997; Dujovny et al., 2004). The latter may play an important role in the future treatment of some neurological conditions (Goldsmith, 2010). The omentum has also been identified as a source of adult stem cells, opening future prospects in the field of tissue engineering and the synthesis of vascular grafts in human medicine (Collins et al., 2009). For extra-peritoneal wounds, the omentum can be harvested for a microsurgical free graft, or it can be mobilized as a pedicle flap (Hultman et al., 2002). Knowledge on the attachment of the omentum to surrounding structures and on its vascular supply is obviously prerequisite for these surgical applications. In fact, in human medicine, the refinement of anatomic knowledge and the development of safe mobilization techniques have paralleled the increased use of the omentum in reconstructive and cardiovascular surgery (Fix and Vasconez, 1989; Hultman et al., 2002). Although dogs and cats have frequently served as research models to explore these omental surgical applications in humans (Goldsmith, 1975; De la Torre and Goldsmith, 1994; Hayari et al., 2004), detailed anatomical data on the canine and feline omenta and their vascular supply are scarce. Consequently, the surgical techniques used in these exploratory studies, as well as those subsequently applied in companion animal patients, often improperly rely on human data.

Furthermore, in microscopic studies on the omentum of small animals, researchers have few anatomical landmarks to meticulously describe the place of sampling (Owaki et al., 2013). As a result, the nomenclature used in the current scientific literature on omental research in dogs 
and cats is based on either non-detailed veterinary anatomical terminology or ill-extrapolated human data.

The main goal of the present study was to map anatomical landmarks that will improve unambiguous scientific communication on the canine omentum. In the second part of the study (Part 2) the recesses of the omental cavity will be described and discussed in detail.

\section{Materials and Methods}

A total of 9 cadavers of dogs of different gender, age and breed were used (Table 1). Different techniques including casting of the blood vessels, dissection of embalmed cadavers and filming of a dissected fresh cadaver were implemented to illustrate observations. All animals had been euthanized for reasons unrelated to this study. In 6 dogs, latex injection and vessel dissections were performed. All dogs were positioned in dorsal recumbency. The thoracic cavity was opened through a rectangular window (approximately $6 \times 4 \mathrm{~cm}$ ) in the left $4^{\text {th }}-6^{\text {th }}$ intercostal space. A 20 Gauge intravenous catheter was placed in the thoracic aorta and secured by an encircling ligature just caudal to the aortic arch, and a 3-way stopcock was connected. Subsequently, 150-700 $\mathrm{ml}$ of an aqueous latex solution (Polyester Demaere $\odot$, Belgium) was injected into the catheter. After curing of the latex for at least 2 hours, the abdominal wall was incised along the ventral midline, and the peritoneal cavity was opened from the xiphoid cartilage to the pecten of the pubic bone to explore and dissect the injected blood vessels. Additionally, the abdominal cavities of 2 female embalmed dogs with injected blood vessels (Carolina's Perfect Solution $($ ), USA) were dissected to confirm previously gained insights and to illustrate some anatomical features more clearly due to the rigidity of the embalmed cadavers (Fig 3). Finally, to illustrate the three-dimensional topographic anatomy of the greater omentum in situ, the omentum of a fresh cadaver was filmed while 
being dissected via a ventral midline approach. The resulting video can be viewed by opening the following URL-link: www.UGent.be/canine-omentum.

\section{$\underline{\text { Results }}$}

In all dogs, the greater omentum was composed of a bursal, a splenic and a veil portion. The former two portions consist of a superficial and a deep wall, whereas the veil portion is a single peritoneal fold. The omentum contains several arteries, of which the topographic anatomy provides the landmarks necessary to delineate the various omental parts.

\section{$\underline{\text { Arterial landmarks }}$}

The omental blood vessels are either located in the fatty streaks of the omental wall or are contained within folds of the superficial wall of the greater omentum, which protrude into the omental bursa (video).

The major blood supply of the bursal portion is derived from the gastroepiploic arterial arch. This anastomosis between the left and right gastroepiploic arteries (A. gastroepiploica sinistra and A. gastroepiploica dextra, respectively) is located in the superficial wall of the bursal portion, parallel to the greater curvature of the gastric corpus and pylorus. The left and right gastroepiploic arteries have a different origin. The right gastroepiploic artery is located in the pyloric region and stems from the short gastroduodenal artery (A. gastroduodenalis), which is a branch from the hepatic artery (A. hepatica) (Fig. 1, video). After arising from the celiac artery (A. celiaca), the hepatic artery courses cranioventrally towards the liver in a peritoneal fold extending from the dorsal abdominal wall, the hepatopancreatic fold (Plica hepatopancreatica) (Fig. 3C). The left gastroepiploic artery stems from the splenic artery (A. lienalis), which arises from the celiac artery and is located in the deep wall of the greater omentum in which it runs parallel to the left pancreatic lobe. At the level of the lateral tip of 
this pancreatic lobe, the splenic artery gives off a large gastrosplenic branch and continues towards the splenic hilus. The gastrosplenic branch gives rise to a splenic branch that supplies the dorsal part of the spleen and a cranial gastric branch that curves ventrally towards the fundus of the stomach and which it supplies by several short gastric arteries (Aa. gastricae breves) (Fig. 1, video). The cranial gastric branch is contained within a fold of the superficial wall of the greater omentum, which will be further referred to as the cranial gastrosplenic fold (Fig. 2). After giving rise to the gastrosplenic branch, the splenic artery continues its course in the deep wall of the greater omentum towards the middle segment of the spleen and proceeds along the splenic hilus. However, before reaching the hilus the artery gives off two strong branches, i.e., the left gastroepiploic artery and a second strong arterial branch that will be further referred to as the caudal gastric branch and that ramifies in short gastric arteries to the gastric fundus (Fig. 1, video). Occasionally, the caudal gastric branch arises directly from the left gastroepiploic artery (Fig. 1). Both the left gastroepiploic artery and the caudal gastric branch are contained in folds of the superficial wall of the splenic portion, designated as the caudal and middle gastrosplenic fold respectively (Fig 2).

\section{Omental portions}

The bursal portion of the greater omentum covers the intestinal coils both ventrally and bilaterally. Its superficial wall originates from the greater curvature of the stomach, extending from the gastric fundus to the pylorus and continuing onto the proximal part of the duodenum in alignment with the attachment of the lesser omentum to the duodenum (Ligamentum hepatoduodenale). The superficial wall extends along the ventral abdominal wall as far as the empty urinary bladder. To the right, caudally and also to the left (i.e., caudal to the spleen) the superficial wall of the bursal portion reflects dorsally and continues as the deep wall. The deep wall of the bursal portion proceeds cranially, attaches to the left lobe of the pancreas, 
encompasses this pancreatic lobe and then continues craniodorsally to attach to the dorsal abdominal wall (Fig 3B). The left cranial edge of the bursal portion is attached to the hilus of the spleen. However, the ventral extremity of the spleen remains unattached to omentum (video). The cranial border of the deep wall of the bursal portion is delineated by the splenic artery (Fig. 1, video).

The splenic portion of the greater omentum also consists of a superficial and a deep wall. At the level of the spleen, i.e., in the left cranial area of the abdomen, the superficial wall of the splenic portion is continuous with the superficial wall of the bursal portion. The border between the superficial walls of the bursal and splenic portions can be set at the level of the caudal gastrosplenic fold containing the left gastroepiploic artery. The superficial wall of the splenic portion is bordered medially by the stomach and laterally by the cranial half of the splenic hilus. The splenic portion then extends further craniodorsally beyond the spleen, forming a cranial protrusion consisting of a superficial and a deep wall. Both walls attach medially to the cardia of the stomach and the oesophagus, and insert cranially on the tendinous centre of the diaphragm, lining the left half of the oesophageal hiatus (Fig. 1, video). The caudal border of the superficial wall of the cranial protrusion is delineated by the cranial gastrosplenic fold, whilst the caudal border of the deep wall of this protrusion is delineated by the gastrosplenic branch of the splenic artery (Fig. 1, video).

Between the cranial and caudal gastrosplenic folds, the superficial wall of the splenic portion forms a semilunar pouch, further referred to as the caudoventral outpocketing of the splenic portion (video).

The deep wall of the splenic portion is divided into cranial and caudal parts by the position of the gastrosplenic branch of the splenic artery. The caudal part is bordered laterally by the splenic hilus and both medially and caudally by the splenic artery which courses towards the 
splenic hilus and delineates the border between the deep walls of the bursal and splenic portions of the greater omentum. The caudal part of the deep wall of the splenic portion forms a semilunar pouch, which is further referred to as the caudodorsal outpocketing of the splenic portion (Fig. 1, video).

The veil portion, which was remarkably large in some dogs, is characterized by a free caudal margin. Its cranial margin originates from the deep wall of the omentum at the level of the splenic artery. The right lateral margin of the veil portion blends with the left side of the mesocolon. The left lateral margin is attached to the ventral part of the visceral side of the spleen. Perpendicular to the left lateral margin a small triangular fat-free fold splits off from the dorsal surface of the veil portion and protrudes towards the spleen (Fig. 3A, video).

\section{Discussion}

The present observations of the canine omentum largely correspond to those described in the literature (Evans, 1993; Barone, 2009). The subdivision of the greater omentum into bursal, splenic and veil portions has been set a long time ago (Zietzschmann, 1939), but the definition of the exact borders between those individual omental portions was lacking until now. Moreover, some previous definitions of omental parts are ambiguous. Since research on the omentum and its clinical applications is increasing, there is a need for clear definitions.

In the present study, we attempted to set consistent and unambiguous borders for omental portions, resulting in specific definitions and a more detailed nomenclature for the canine omentum. To a large extent, these margins are defined by arterial landmarks. The smaller proper omental arteries run in the fatty streaks of the omental walls while some of the larger arteries, supplying the omentum and the attached organs (stomach and spleen), are contained within folds of the superficial wall of the greater omentum that protrude into the bursal cavity 
of the omentum. These arteries provide some of the landmarks that are necessary to define the various parts of the omentum properly.

The canine splenic artery presents a variable branching pattern resulting in a variety of descriptions and confusing nomenclature in the literature (Gravenstein, 1938; Horst, 1941; Godinho, 1964). Yet, some consistent findings were confirmed in the present study. Shortly after its origin from the celiac artery, the splenic artery bifurcates into a proximal and a distal branch (Gravenstein, 1938; Horst, 1941; Godinho, 1964; Barone, 1996). In all cases in the present study, this bifurcation was situated at the level of the lateral tip of the left pancreatic lobe. The proximal branch provides blood supply to the dorsal part of the spleen (through splenic branches) and additionally to the stomach (through short gastric arteries) (Gravenstein, 1938; Horst, 1941). This proximal branch corresponds to the gastrosplenic branch as defined in international nomenclature in pigs (Simoens, 2012). It was previously described as occasionally double and contained within a fold of the superficial wall of the splenic portion (Gravenstein, 1938; Horst, 1941). We found in all cases a single gastrosplenic branch, which ramified into a splenic branch and a cranial gastric branch. The latter was contained within the cranial gastrosplenic fold of the superficial wall of the splenic portion. The splenic artery proceeds its course towards the splenic hilus. Before reaching the hilus, it gives rise to the left gastroepiploic artery, which is also contained in a fold of the superficial omental wall (Gravenstein, 1938, Horst, 1941, Evans, 1993). This fold, which we named the caudal gastrosplenic fold, is located in the transition zone between the superficial walls of the bursal and splenic portions (Horst, 1941). Hence, it serves as a clear and consistent border between both omental portions.

The short gastric arteries arise from the cranial gastric branch and the left gastroepiploic artery, but they can also originate from an additional arterial branch, which was previously described as originating directly from the splenic artery (Gravenstein, 1938) or from the left 
gastroepiploic artery (Horst, 1941). This double origin was confirmed in the present study as both were observed and we designated this branch as the caudal gastric branch. It was consistently present and was contained within the middle gastrosplenic fold, serving as a landmark to define the splenic portion. A variety of smaller additional branches of the splenic artery have been described in the literature (Gravenstein, 1938, Horst, 1941) and were also found in the present study. Given their inconsistent pattern they cannot serve as landmarks to define omental portions. The same is true for smaller arteries that supplied the splenic portion itself and arose from the splenic artery or from one of its major branches. Those arteries ran superficially and in variable patterns in the fatty streaks of the splenic portion.

A precise delineation and definition of the gastrosplenic (Ligamentum gastrolienale), gastrophrenic (Ligamentum gastrophrenicum) and phrenicosplenic (Ligamentum phrenicolienale) ligaments is lacking in traditional descriptions and in official nomenclature. The gastrosplenic ligament extends from the greater curvature of the gastric fundus to the spleen (Habel, 2012). The attachment of the spleen to the superficial wall of the omentum has been considered as the cranial border of the gastrosplenic ligament (Barone, 2001). No clear caudal border has been defined. In the present observations, the gastrosplenic ligament was bordered cranially by the cranial gastrosplenic fold and caudally by the caudal gastrosplenic fold. While this gastrosplenic ligament could clearly be defined, we failed to observe a distinct gastrophrenic ligament, which has been described as a short and robust ligament loaded with fibro-elastic fibers (Barone, 2001). It has been reported as extending between the gastric fundus and the diaphragm and continuing to the left as the phrenicosplenic ligament, which connects the diaphragm and the spleen (Barone, 2001; Barone, 2009; Habel, 2012). These ligaments have been assigned a suspensory role of the stomach and the spleen, respectively (Barone, 2001). Such strong and well delineated ligaments could not be 
demonstrated in the present study, but instead we observed a cranial protrusion of the splenic portion of the greater omentum, composed of both a superficial and a deep wall. This protrusion consisted of loose omental tissue, making a suspensory role doubtful. Considering these findings, one might question whether the term ligament is appropriate for this structure since a ligament is defined as an inelastic structure that joins two organs or connects an organ to the body wall in a solid way (Barone, 2001).

The gastrosplenic ligament has been considered as a synonym of the splenic portion of the greater omentum (Evans, 1993; Barone, 2001; Budras, 2002; Könich and Liebich, 2004; Barone, 2009). Based on the present findings, however, both terms are not synonymous because the splenic portion is an omental portion with a superficial and a deep wall, and includes a cranial protrusion that extends craniodorsally beyond the cranial margin and the dorsal extremity of the spleen. In contrast, the gastrosplenic ligament is a mere part of the superficial wall of the splenic portion, bordered by the cranial and caudal gastrosplenic folds.

The veil portion of the omentum (Velum omentale) is the sagittal membrane that connects the deep wall of the greater omentum with the left surface of the descending mesocolon (Habel, 2012). According to some authors (Evans, 1993), it contains the distal extremity of the left pancreatic lobe. This could not be confirmed in the present study. Other discrepancies were noted concerning the free margin of the veil portion, which has been described as a left free margin (Evans, 1993), whereas we observed a caudal free margin in the present study.

The findings of the present study lead to a number of recommendations for elaboration of the existing official nomenclature (N.A.V, 2012). In addition to the Plica hepatopancreatica and the Plica gastropancreatica, which are listed in the current N.A.V., it is suggested to include also the terms Plica gastrolienalis cranialis, Plica gastrolienalis intermedia and Plica gastrolienalis caudalis for designating the omental folds that were observed consistently in the 
present study and contain major blood vessels which form valuable topographic landmarks for delineating various omental parts.

In contrast, the Ligamentum gastrophrenicum and the Ligamentum phrenicolienale, which are listed in N.A.V. without any species designations, were not observed as clearly delineated structures in any of the dogs examined in the present study.

Similar to the situation in pigs, a gastrosplenic branch was given off by the A. lienalis in all examined dogs and therefore, it is suggested to list the term Ramus gastrolienalis for both the porcine and canine species. Furthermore, two constant arterial branches were given off either indirectly or directly by the A. lienalis in all dogs examined, and they were designated as the Ramus gastricus cranialis and the Ramus gastrolienalis caudalis, respectively.

\section{Acknowledgments}

The authors wish to thank Bart De Pauw for his excellent technical assistance.

\section{$\underline{\text { References }}$}

- Barone, R., 1996: Tome 5, Angiologie. Anatomie Comparée des Mammifères Domestiques. Paris: Editions Vigot, 904 pp.

- Barone, R., 2001: Tome 4, Splanchnologie 2: Appareil uro-génital, foetus et ses annexes, péritoine et topographie abdominale. Anatomie Comparée des Mammifères Domestiques. Paris: Editions Vigot, 896 pp.

- Barone, R., 2009: Tome 3, Splanchnologie 1: Appareil digestif et appareil respiratoire. Anatomie Comparée des Mammifères Domestiques. Paris: Editions Vigot, 951 pp.

- Budras K-D., and P.H. McCarthy, 2002: Anatomy of the dog. An illustrated text. $4^{\text {th }}$ edn. Hannover: Schlütersche, 218 pp.

- Collins, D., Hogan, A.M., O’Shea, D., and D.C. Winter, 2009: The omentum: Anatomical, metabolic, and surgical aspects. J. Gastrointest. Surg. 13, 1138-1146.

- De la Torre, J.C., and H.S. Goldsmith, 1988: Can transected spinal cord axons be bribed into regeneration? In: The omentum. Research and clinical implications (H.S. Goldsmith ed.). New-York: Springer-Verlag, 63-73 pp. 
- De La Torre, J.C., and H.S. Goldsmith, 1994: Coerulospinal fiber regeneration in transected feline spinal cord. Brain Res. Bull. 35, 413-417.

- Dujovny, M., Ding, Y.H., Ding, Y., Agner, C., and P.A. Eimir, 2004: Current concepts on the expression of neurotrophins in the greater omentum. Neurol. Res. 26, 226-229.

- Evans, H., 1993. The digestive apparatus and abdomen. In: Miller's Anatomy of the dog. $3^{\text {rd }}$ edn. (H. Evans ed.). Philadelphia: W.B. Saunders Company, 386-465 pp.

- Fix, R.J., and L.O. Vasconez, 1989: Use of the omentum in chest-wall reconstruction. Surg. Clin. North Am. 69, 1029-1046.

- Godinho, H.P., 1964: Estudo anatõmico da terminação e anastomoses da A. lienalis e as zonas (segmentos) anteriais lienais em canis familiaris. Arq. Esc. Vet. 16, 163-196.

- Goldsmith, H.S., 1975: Prevention of cerebral infarction in the dog by intact omentum. Am. J. Surg. 130, 317-320.

- Goldsmith, H.S., 2010: Applications of the omentum to the brain and spinal cord. In: The omentum. Research and clinical implications (H.S. Goldsmith ed.). New-York: Springer-Verlag, 37-52 pp.

- Gravenstein, H., 1938: Über die Arterien des grossen Netzes beim Hunden. Morph. Jahrb. 82, 1-26.

- Gray, M.J., 2005: Chronic axillary wound repair in a cat with omentalisation and omocervical skin flap. J. Small Anim. Pract. 46, 499-503.

- Habel, R.E., 2012: Splanchnologia. In: Illustrated Veterinary Anatomical Verlag, 140-233 pp.

- Hayari, L., Hershko, D. D., Shoshani, H., Maor, R., Mordecovich, D., and G. Shoshani , 2004: Omentopexy improves vascularization and decreases stricture formation of esophageal anastomoses in a dog model. J. Pediatr. Surg. 39, 540-544.

- Horst, T., 1941: Die arterielle Blutversorgung des Magendarmkanals, seiner Anhangsdru $\square$ sen (Leber, Pankreas) und der Milz beim Hunde. Morph. Jahrb. 85, 417446.

- Hultman, C.S., Carlson, G.W., Losken, A., Jones, G., Culbertson, J., Mackay, G., Bostwick, J., and M.J. Jurkiewicz, 2002: Utility of the omentum in the reconstruction of complex extraperitoneal wounds and defects. Ann. Surg. 235, 782-795. 
- Ito, K.C., Ferrigno, C.R.A., and F.R. Alves, 2010: Maximum length of greater omentum pedicle flap through subcutaneous tunnel for long bones in dogs. Ciênc. Rur. 40, 594-599.

- Könich H.E., and H-G Liebich, 2004: Veterinary Anatomy of Domestic Animals. Textbook and Colour Atlas. Stuttgard: Schattauer, $681 \mathrm{pp}$.

- Liebermann-Meffert, D., 2000: The greater omentum. Anatomy, embryology and surgical applications. Surg. Clin. North Am. 80, 275-293.

- McGready, T.A., Quinn, P.J., Fitz Patrick, E.S., and M.T. Ryan, 2006: Veterinary Embryology. Oxford: Blackwell Publishing, 377 pp.

- Noden, D.M., and A. De Lahunta, 1985: The embryology of domestic animals. Developmental mechanisms and malformations. London: Wiliams \& Wilkins, 367 pp.

- Owaki, M., H. Oono, Nakajima N., Ohta G., Okano S., Kakizaki T. and K. Yoshioka, 2013: Scanning electron microscopic study for pore formation of the greater omentum. Anat. Histol. Embryol. 42, 151-154.

- Ross, W.E., and A.D. Pardo, 1993: Evaluation of an omental pedicle extension technique in the dog. Vet. Surg. 22, 37-43.

- Simoens, P.J., 2012: Angiology. In: Illustrated Veterinary Anatomical Nomenclature. (G.M. Constantinescu, G.M., and O. Schaller eds.). Stuttgart: Enke Verlag, 140-233 pp.

- Valat, B., and P. Moisonnier, 2004: The omentum: “The surgeon's friend”. Eur. J. Comp. Anim. Pract. 14, 57-67.

- White, R.A.S., and J.M. Williams, 1995: Intracapsular Prostatic Omentalization: A new technique for management of prostatic abscesses in dogs. Vet. Surg. 24, 390-395.

- World Association of Veterinary Anatomists, 2012: Nomina Anatomica Veterinaria $\left(5^{\text {th }}\right.$, revised version), Editorial Committee, Hamburg, Columbia, Ghent, Sapporo, 160 pp. http://www.wava-amav.org/nav_nev.htm 
393 Table 1: List of dogs and techniques used in the present study

\begin{tabular}{|c|c|c|c|}
\hline Breed & Age group & $\begin{array}{c}\operatorname{Sex}(\mathrm{F}=\text { female, } \mathrm{M}= \\
\text { male })\end{array}$ & Implemented techniques \\
\hline $\begin{array}{l}\text { American } \\
\text { Stafford }\end{array}$ & $\begin{array}{l}\text { Young } \\
\text { Adult }\end{array}$ & F neutered & Vascular casting with latex \\
\hline $\begin{array}{l}\text { English Cocker } \\
\text { Spaniel }\end{array}$ & $\begin{array}{l}\text { Young } \\
\text { Adult }\end{array}$ & $\mathrm{F}$ & Vascular casting with latex \\
\hline $\begin{array}{l}\text { American } \\
\text { Stafford }\end{array}$ & $\begin{array}{l}\text { Young } \\
\text { Adult }\end{array}$ & M neutered & Vascular casting with latex \\
\hline Mongrel dog & $\begin{array}{l}\text { Young } \\
\text { Adult }\end{array}$ & $\mathrm{M}$ & Vascular casting with latex \\
\hline $\begin{array}{l}\text { Jack Russell } \\
\text { terrier }\end{array}$ & $\begin{array}{l}\text { Adult- } \\
\text { Geriatric }\end{array}$ & $\mathrm{F}$ & Vascular casting with latex \\
\hline Cairn terrier & $\begin{array}{l}\text { Young } \\
\text { Adult }\end{array}$ & $\mathrm{F}$ & Vascular casting with latex \\
\hline Mongrel dog & $\begin{array}{l}\text { Young } \\
\text { Adult }\end{array}$ & $\mathrm{F}$ & $\begin{array}{c}\text { Embalmed with injected blood } \\
\text { vessels }(*)\end{array}$ \\
\hline Mongrel dog & $\begin{array}{l}\text { Young } \\
\text { Adult }\end{array}$ & $\mathrm{F}$ & $\begin{array}{c}\text { Embalmed with injected blood } \\
\text { vessels }(*)\end{array}$ \\
\hline Rottweiler & Immature & $\mathrm{F}$ & Dissection+video \\
\hline
\end{tabular}

(*Carolina's Perfect Solution $@$, preserved dog, double color injected) 
406

407

408

409

410

411

412

413

414

415

416

417

418

419

420

421

422

423

424

425

426

427

428

429

430

431

432

433

a. Oesophagus, b. Stomach, c. Duodenum, d. Spleen, e. Papillary process of the caudate lobe of the liver, f. Descending colon, g. Transverse colon, h. Left pancreatic lobe, i. Left kidney, j. Bursal portion (j' superficial wall, j" deep wall), k. Splenic portion (k' superficial wall, k" deep wall), 1. Veil portion, m. Cranial gastrosplenic fold, n. Middle gastrosplenic fold, o. Caudal gastrosplenic fold, p. Part of the tendinous centre of the diaphragm, q. Attachment of the deep omental wall to the dorsal abdominal wall (transected)

1. Aorta, 2. Celiac artery, 3. Left gastric artery, 4. Hepatic artery, 5. Splenic artery, 6. Gastrosplenic branch (6'. Splenic branch, 6". Cranial gastric branch), 7. Left gastroepiploic artery, 8. Caudal gastric branch, 9. Short gastric arteries, 10. Right gastric artery, 11. Gastroduodenal artery, 12. Right gastroepiploic artery

Fig. 1: Schematic drawing of abdominal organs (stomach, spleen and left lobe of the pancreas) with supplying arteries and attached omentum, based on cadaveric dissections. A: Ventral view. B: Dorsal view.

Fig. 2: A: Caudal-to-cranial view into the omental bursa, approached through an incision and subsequently lifting of the superficial wall of the bursal portion. B: Oblique right-to-left view of the gastrosplenic ligament. The wall of the ligament holds three gastrosplenic folds that contain large blood vessels. These folds do not smoothen when tension is applied on the ligament.

Fig. 3: A, B, C: Caudal-to-cranial views of the cranial abdominal viscera of an embalmed dog A: The right lateral margin of the omental veil portion blends with the left side of the descending mesocolon. The asterisk indicates the fat-free fold that splits off from the left lateral side of the omental veil and attaches to the visceral surface of the spleen. B: The transverse colon is retracted dorsally to show the attachment of the deep wall of bursal portion of the greater omentum (j") to the left pancreatic lobe (h) (asterisks). C: The omental bursa is opened by transecting the deep wall of the bursal portion from its attachment to the left pancreatic lobe which is reflected dorsally. The single arrow indicates the hepatopancreatic fold (with the hepatic artery) and the double arrows point to the gastropancreatic fold (with the left gastric artery). 